\title{
How Do Students View Asynchronous Online Discussions As A Learning Experience?
}

\author{
Penny Bassett \\ Victoria University, Melbourne, Australia
}

penny.bassett@vu.edu.au

\begin{abstract}
This case study explores students' perceptions of the value of asynchronous online discussions. Postgraduate business students participated in asynchronous online discussions that are part of a blended approach to teaching, learning, and assessment. The students were required to read three refereed journal articles on global human resource information system (HRIS) implementations, write annotated bibliographies, discuss online in groups of four, and reflect on the learning experience. Students' reflections are examined to identify factors that make this a worthwhile learning experience. These reflections indicate that students valued the learning experience and viewed the online environment as an inclusive place in which to collaborate and discuss with their peers. Planning, preparation, and structure were found to be factors relating to the effectiveness of the online discussion, with timing generally being viewed as positive but seen as an issue by some students. Overall, students valued this learning and assessment strategy believing that it increased their knowledge and understanding of HRIS.
\end{abstract}

Keywords: Asynchronous online discussion; collaboration; student reflections; blended learning

\section{Introduction}

One of the challenges in many Australian universities is to provide learning and assessment experiences that cater for an increasingly diverse student population. This study has been undertaken in one of the most culturally diverse Australian universities with a philosophy that the curriculum should be inclusive and "equally relevant to local and international students" (Woodley \& Pearce, 2007, p.2). In this paper it is contended that an asynchronous online discussion, in a blended approach to learning and assessment, can facilitate an inclusive learning environment.

A vital component of the blended approach is integration of learning and assessment activities, with each complementing the other in achieving learning outcomes. In relation to online discussions, this is supported by Zhu (2006) and Groves and O'Donoghue (2009) who contend that there should be alignment with curriculum objectives. The online activity in this study is part of a blended approach to learning and assessment designed to develop knowledge, understanding and

Material published as part of this publication, either on-line or in print, is copyrighted by the Informing Science Institute. Permission to make digital or paper copy of part or all of these works for personal or classroom use is granted without fee provided that the copies are not made or distributed for profit or commercial advantage AND that copies 1) bear this notice in full and 2) give the full citation on the first page. It is permissible to abstract these works so long as credit is given. To copy in all other cases or to republish or to post on a server or to redistribute to lists requires specific permission and payment of a fee. Contact Publisher@InformingScience.org to request redistribution permission. critical skills for use in subsequent assignments.

Previous studies found that, while many English as a second language (ESL) students lack confidence and are hesitant to participate in face-to-face discussions, these factors are alleviated in collaborative asynchronous online discussions (Al-Salman, 2009; Gerbic, 2010). An aim of learning is to enable students to 
work together in sharing knowledge and developing understanding. Palloff and Pratt (1999, as cited in Vonderwell, 2003) believe that this collaboration leads to the development of new meaning, with Macdonald (2008, p.115) pointing out that student-centered learning online includes "einvestigation, e-writing and e-collaborating."

Other researchers have examined various factors that relate to the success and limitations of asynchronous online discussions (for example, Andresen, 2009; Gerbic, 2006). These include structure, timing, group size, instructor presence/absence, incentives, collaboration, and the online environment itself.

Using a single case-study research methodology, this research explores asynchronous online discussions as a learning and assessment strategy from the students' perspectives. Feedback from student reflections, submitted as a component of the online discussion assessment requirements, was examined to identify whether student learning was enhanced through this learning experience and what factors contributed this.

\section{Context and Background}

Over a period of many years postgraduate students in the subject human resource information systems (HRIS) have shown a reluctance to discuss in face-to-face learning situations, so it was decided to include an online, asynchronous discussion in the curriculum. The structure and guidelines have been reviewed and refined as it has evolved into a well-structured learning and assessment strategy in a blended curriculum.

There has been an increasing number of ESL students in the subject, and they now outnumber the Australians who are native English speakers. In 2010 there was a ratio of 80:10 ESL to native English speakers in HRIS. An ongoing area of concern is that during the classroom discussions responses are often directed to the lecturer rather than to each other, and there is limited participation. It is also difficult to get Australian students to interact or work collaboratively with international students.

Macdonald (2008) states that with online discussions it is possible to assess individual contributions. While the online discussion is a collaborative activity, in this study the assessment is marked individually and consists of an annotated bibliography, contributions to the discussion demonstrating understanding of the topics, and a short reflection on the learning experience. The rationale for this is that all students are required to read and annotate three articles that provide the basis for the discussion and this and the reflections are obviously individual activities. Previously, students collaborated on all aspects of this assignment, dividing the tasks, particularly the annotated bibliography. In some cases students read only the article they annotated which subsequently affected the quality of the discussions.

The structure of this online discussion has evolved over many years from a relatively loosely structured activity with few instructions on how to engage in the discussions to a finely structured assessment related learning experience including clearly stated criteria, guidelines, and timelines, with the individual contributions to the online discussion being assessed. According to Gerbic (2010) students need to be motivated to participate in online discussions, with well-planned and structured learning and assessment activities. This is supported by Vonderwell, Liang and Alderman (2007), who suggest that the structure of a discussion influences student participation and subsequently how they value the assessment in the online learning environment. Further, Yeh and Buskirk (2005, as cited in Hew, Cheung \& Ng, 2010) found that assessing the discussion encouraged students to engage in the learning activity. Andressen (2009, p.252) also states that "many learners need an incentive to participate," suggesting that the degree of participation be included in the assessment. 
Alignment with curriculum objectives and integration of learning and assessment activities are essential factors in blended learning (Groves and O'Donoghue, 2009; Zhu, 2006). Learning outcomes and assessment guidelines in this subject are explicitly written to demonstrate alignment with the curriculum objectives in the online discussion and other learning and assessment activities in the subject (see the Appendix).

The students are randomly organized into groups of four or five, although sometimes groups fall to three because of student attrition. While the Du, Zhang, Olinzock, and Adams' (2009) study suggests that groups of three to four students are preferable, four was found to be the optimal size in this case, with groups of three usually having less in-depth, shorter discussions and often more difficulties with collaboration.

Gerbic (2010) found that preparation for online discussions and explanation of the link between assessment and learning provides an incentive for effective online participation. While the assumption was made that students would be familiar with using web-based materials, in fact they had seldom used interactive web-based learning materials and had to be given practice sessions. Bonk and Zhang (2008) emphasize it is important that students are provided with rules and guidance on online discussion participation, as well as training if required.

Groups were given time in class to introduce themselves, select questions, and discuss how they would organize their time. As well, they were given the opportunity to practice participating in an online asynchronous threaded discussion based on a short journal article. They were encouraged to engage in a discussion rather than simply posting statements, and it was emphasized that the subsequent online discussions would be assessed on demonstration of knowledge, participation and facilitating the on-going discussion through phrases, such as What do you think? I agree (or disagree) but would like to add, etc. Also, students were required to open and close one discussion thread each, as in the 'real' online discussion.

A decision was made to have no lecturer participation in the online discussion. However, the discussion was teacher facilitated in terms of providing the structure through the questions posed but with the discussion and each question being peer-facilitated, similar to $\mathrm{Ng}$, Cheung, and Hew's (2009) study. When the online discussions were first incorporated into the subject, the lecturer participated, commenting regularly on student contributions. This inhibited discussion, resulting in answers being directed to the lecturer rather than fellow students.

While Vonderwell et al.'s (2007) study showed mixed findings on instructor participation: one group of students was found to direct their responses to instructors. Zhu (2006) comments that the instructor's presence may negatively affect student participation and this had been noticed in relation to earlier online discussions in the same subject. Indeed, Gerbic (2010, p.133) suggests that the students take responsibility for the discussion with the absence of the lecturer, "creating a democratic space." As mentioned previously, in face-to-face discussions and lectures it was observed that many students were reluctant to discuss, and this is one of the main reasons the online learning and assessment strategy was adopted.

Gerbic (2010) found that shy students felt less inhibited in the online discussion environment, while Al-Salman (2009, p.12) believes that "online communication allows more intimidated people to participate." In an asynchronous online discussion students have time to read and research before posting answers (Gerbic, 2010). It was observed in earlier iterations of this learning activity that international students found the online environment a safe one in which their research and ideas are respected. This aligns with Hassam's (2007, p.81) contention that 'developing students' self-confidence and allowing that knowledge to surface will encourage the kind of critical thinking overseas students are too often accused of lacking.

This case study explores how a culturally diverse group of students perceive asynchronous online discussions as a learning experience, particularly in terms of collaboration and structure. 


\section{Methodology}

A qualitative, single case study methodology was used as the research aimed to examine students' perceptions of asynchronous online discussions as a learning strategy. Yin (2009) suggests that this methodology is suited to situations where the research is providing an explanation for a 'how' question in a contemporary context; in this case, how students perceive a learning activity in an online environment.

In an online asynchronous discussion assignment, students were required to read and annotate three refereed journal articles, discuss online over a five day period, and reflect on the learning experience. Discussions on a minimum of three questions based on the readings were mandatory with students having the choice of basing the fourth question on the articles or to respond to an open question that invited them to discuss their relevant professional experiences. In groups of four each student had to open one discussion thread on the first day of the discussion, participate in the discussion, and provide a summary closing as well as participate in the other questions selected by the specific group. Marks were allocated individually for an annotated bibliography, the discussion, and the reflection. Details of the assignment are shown in the Appendix.

It was emphasized to students that their reflections would provide feedback that would be used to improve the learning experience and assessment. While submission of the reflection was mandatory, students were informed that they would receive full marks for this component of the assessment if they reflected on either positive or negative aspects of the learning experience rather than on the content of the articles. As the reflection is subjective, marks were lost only for nonsubmission of the reflection.

\section{The Participants}

The 90 students who participated in this study were enrolled in HRIS, a post-graduate unit at Victoria University, Melbourne, Australia in 2010. 72 students were international students for whom English was their second language; 8 were domestic students with English as their second language; 10 were domestic students whose first language was English. Online discussion groups of four were randomly organized using the Blackboard group manager tool.

\section{Tools}

The online discussions took place in the Blackboard learning management system.

\section{Data collection and analysis}

Data was collected from student reflections in response to the assessment requirement to "reflect on the value of this on-line discussion as a learning experience (a personal reflection of no more than half a page). The open statement was used in order to give students flexibility in their responses as well to collect a broad range of qualitative data (Yin 2010).

The reflections were analyzed in order to identify themes and percentages were calculated for each theme.

\section{Results}

The results in Table 1 show that the majority of students $(66 \%)$ positively valued the collaborative group work. Sixteen (18\%) of students expressed positive views about the structure. While $22 \%$ of the students commented favorably on timing, $11 \%$ found the timekeeping of other students an issue. Sixteen (18\%) of the participants reflected that they felt the online discussion provided an inclusive and safe environment. Twenty-one (23\%) of participants either completed the reflection incorrectly or did not submit one. 
Table 1: Themes identified in student reflections

\begin{tabular}{|l|l|l|l|l|l|l|}
\hline \multicolumn{2}{|c|}{ Collaboration } & \multicolumn{1}{|c|}{ Structure } & \multicolumn{2}{c|}{ Timing } & \multicolumn{1}{c|}{ Inclusion } & $\begin{array}{l}\text { Invalid/no } \\
\text { response }\end{array}$ \\
\hline Positive & Negative & Well-structured & Good & Poor & Felt included & $23 \%(21)$ \\
\hline $66 \%(59)$ & $4 \%(4)$ & $18 \%(16)$ & $22 \%(20)$ & $11 \%(10)$ & $18 \%(16)$ & 230 \\
\hline
\end{tabular}
$n=90$

\section{Collaborative Learning}

Both local and international students valued collaborating online and believed they learnt from each other's views and experiences.

It permits people to share their ideas with others and this enables us to learn from each other and, at the same time, it is also an opportunity to discuss different points of view, which is very enrichful.

Students also appreciated seeing other students' perspectives believing this stimulated their thinking and extended their knowledge through interaction with their peers.

This particular exercise has encouraged exchanging of ideas and sharing of experiences among our team members. It has promoted working in a team and stimulated our critical thinking. Furthermore, this activity allowed us to know each team member better and appreciate our differences in opinion and interpretation of the articles. Coming from diverse backgrounds, each one of us has different views that contributed to an engaging and fruitful discussion. This activity has enabled us to learn more from each other's experiences and made us think beyond classroom lectures and textbooks.

Furthermore, the open question for students with professional experience proved a learning experience for some groups.

Fellow group members shared their experiences by comparing the factors pointed from the articles to their previous organizations' practices. Each member was able to share unique experiences, as we were from different industry backgrounds. By scrutinizing the different experiences shared, we noted that different organizations had varied approaches to HR. Also, as none of us have in-depth knowledge or firsthand experience working in HR departments, I feel that the discussions have given us much to reflect about this subject. Such as how organizations feel towards taking a strategic approach to $H R$, the challenges met by project teams implementing HRIS, the factors that can affect HRIS implementations, just to name a few points. I will now be better able to apply ourselves, with the knowledge gained through these discussions if I find myself working in an HRIS implementation.

In any collaborative exercise there will be some issues and this often includes lack of preparation, as was the case in one group.

Ifelt that another problem with the discussion was that certain group members did not read both articles and as such were unsure of how to properly discuss questions.

While it is obvious that the majority of students valued the online discussion as a learning experience, in terms of collaboration an international student puts it in a nutshell in the following comment.

I felt valued and supported by the other members of the group I enjoyed learning from my group members, who always seemed to set a good example and always had the answer. I finished the assignment on an emotional high. 
While inclusion was identified as a separate theme, many of the comments related to the inclusive nature of the collaboration.

\section{Structure}

The structure of the learning and assessment experience was commented on by sixteen students and viewed as an incentive to collaboration and participation, as shown in the following reflection by a local student.

Although I have completed an online discussion previously in another subject, this one was more worthwhile as the approach of delivering and commenting on information was very structured. This assisted all group members in planning their responses and encouraged all to make valuable contributions that drew on and discussed the previous ideas that were presented.

An international student believed that the structure has improved his communication skills.

There were clear instructions set and I have discovered that individually, this structure has enabled me to be a more effective communicator.

The preparation for the online discussion was commented on, with students appreciating the chance to clarify the issues.

The online discussion was a new experience for me. Getting used to the system took a bit of time. However, with the 'dummy' discussion that was set up for class time, it was easy to carry out the real discussion.

While assessment was not reflected upon, it was part of the structure and obviously motivated the students to engage in the discussions.

\section{Timing}

There were thirty reflections on timing, mostly on the positive value of a structured assignment with timelines. However, some students felt there was insufficient time and that other students did not respect the timeline, leading to feelings of frustration.

One student compared the traditional classroom discussion to the online discussion, believing that it was intellectually stimulating and allowed more time for developing insight.

It provides a platform for people to share their knowledge and experience freely without lots of time constraints. Compared to traditional discussion approaches, I think online discussion could be intelligence stimulating. First of all, without pressure on thinking, it is easier for people to think thoroughly and provide relevant as well as insightful ideas. In traditional approach, people are likely to be stressful in creative thinking within a limited time.

The other positive aspect was flexibility where students can communicate online rather than at a specific venue.

Another positive aspect is that we were not limited to a specific time and place (just in the classroom) and had the freedom to participate at the place and time we are comfortable, of course within a timeframe.

While there were few negative responses, some reflections included statements such as:

One member left their responses till quite late and I think missed valuable opportunities to expand on some discussions. 
In common with many collaborative exercises there will be some students who participate in a limited manner, but overall the timing of the asynchronous online discussion was perceived as satisfactory.

\section{Inclusive Learning Environment}

With a majority of ESL students in this subject there were a relatively small number of reflections on how their confidence increased in the online environment. However, an international student's reflection on this is typical of other comments.

It is very useful because it helps me as an international student to give me time to type organized sentences in a good English. If this discussion in the class, then I could not say everything I want to say as it is provided in the e-discussion because we are usually shy to speak quickly which will leads us to speak with no English grammar.

While some students were more confident in the online discussion, one local student found the lack of debate interesting but obviously conformed to the group norm in her responses.

I wonder how much 'culture' influences the discussion. I wonder if it is culturally acceptable to openly disagree with another student's point of view. Even without the cultural overlay, I found it very difficult to disagree with another student's point of view as I thought I might inadvertently offend another person. I think every person in my group (without exception) agreed with each other across the three articles and the five questions.

As mentioned previously, many of the reflections on collaboration indicated that the online discussion was inclusive, increasing knowledge and understanding through the exchange of ideas in a more flexible learning environment.

\section{Discussion}

Learning from each other and developing understanding were valued by the majority of students in the collaborative online context. Groves and O'Donoghue $(2009$, p. 148) observed, with some reservations, that an asynchronous exercise "seemed to enhance the learning experience of the students." In most reflections collaboration was specifically linked to the learning experience: learning from each other; self-insight about information systems issues; transfer of learning to the work situation. All of these factors indicate that students view the online environment as an inclusive one.

A number of students appreciated the structure, with one student favorably comparing this online discussion to another one she had participated in. This supports Vonderwell et al.'s (2007, p.321) finding that "structure is an essential factor in the design, implementation and assessment of asynchronous discussions." As Bonk and Zhang (2008) point out, rules and guidelines are essential and in this study the practice discussion was useful in highlighting the need for structure and preparation.

While timelines were incorporated into the design of the discussion, time management has always been an issue in this learning exercise. Fewer students reflected on timing but those that did commented favorably about the flexibility of time, stating that it allowed them to consider the questions and concepts and thus discuss more critically or creatively. Gerbac's (2006) study supports this, finding that there was time for students to research and consider their responses before engaging in the discussion. However some students had concerns about group members' time management, with this affecting the quality of the discussion. This factor has been noted more in relation to less structured asynchronous discussions that are not related to assessment (Groves \& O’Donoghue, 2009). 
There was a low response rate for inclusion, a concept that was narrowly defined in this study. However, a number of reflections related to both inclusion and collaboration illustrated that the online discussion increased ESL students' confidence. They felt less shy and had time to think about and outline their contributions, alleviating the fear of a poorly phrased answer. While this may limit the spontaneity of responses it also provided an opportunity for clarifying concepts for a more insightful reply and allowed them to interact with their group more comfortably. As Hassam (2007) explains, it is essential to develop international students' confidence to enable them to become critical thinkers.

In regard to inclusion and collaboration, an interesting cultural factor emerged with an Australian student finding that there was a reluctance to disagree with any responses. She was in a group with three international students and the hesitation to contribute what might be perceived as negative comments could relate to $\mathrm{Ng}$ et al.'s (2009) similar findings with a group of Asian students.

\section{Conclusion}

The online discussion was designed as part of a blended approach to learning, and, while it appears to be a successful learning strategy that students valued, the present study did not explore the link between the various components of the curriculum. The exercise itself certainly integrated learning and assessment activities in achieving the learning outcomes (Groves \& O'Donoghue, 2009; Zhu, 2006), but further research is required to explore whether the linkage between the various learning and assessment components of this HRIS subject was realized. The themes identified were similar to those found in previous studies; that is, collaboration, structure, timing, and inclusive learning experiences.

In this research, the students highly valued the collaborative nature of the discussion in the online environment. Collaboration and its many facets will be the topic of the next study on online discussions; in particular, the concept of inclusion and its relationship to collaboration will be explored. While themes were identified and enumerated in the present study, in the future formal coding and analysis of the qualitative data will be used in order to develop a greater understanding of the nature of online collaboration.

Guidelines, structure, and timing are obvious factors that affect participation and learning in this study, appearing to support that a well structured asynchronous online discussion with clear guidelines and outcomes facilitates learning and collaboration.

In a culturally diverse class both Australian and international students had positive reflections on the learning experience and, it is contended, this was partly due to the fact that while the discussions were collaborative the students were assessed individually. A tentative conclusion can be made that the collaborative nature of the online discussions facilitated an inclusive learning experience for all students. There was a noticeable lack of disagreement in one group, and it would be interesting to investigate cultural factors relating to inclusiveness and intercultural communication in a future study.

Overall, the asynchronous online discussion was perceived as a valuable learning strategy that resulted in increased confidence to interact in a collaborative online environment. Most students believed their knowledge, understanding, and critical ability were enhanced in this inclusive context. The following reflection from one of the students sums this up.

On reflection there were a number of positive outcomes and a few barriers to a full and frank discussion. The first positive was that this was a new and interesting exercise; in short it was an enjoyable exercise. The process also helped develop relationships with fellow students and it was good to see different perspectives after reading the same article. 
In conclusion, this study provides the basis for further research on asynchronous online discussion. In particular, a more rigorous examination of collaboration and inclusion in the online learning environment from a broader perspective is required.

\section{References}

Al-Salman, S. M. (2009). The role of the asynchronous discussion forum in online communication. Journal of Instruction Delivery Systems, 23(2), 8-13.

Andresen, M. A. (2009). Asynchronous discussion forums: Success factors, outcomes, assessments and limitations. Educational Technology and Society, 12(1), 249-257.

Bonk, C. J., \& Zhang, K. (2008). Empowering online learning: 100+ Activities for reading, reflecting, displaying, and doing. Hoboken, USA: Jossey-Bass.

Du, J., Zhang, K., Olinzock, A., \& Adams, J. (2008). Graduate students' perspectives on the meaningful nature of online discussions. Journal of Interactive Learning Research, 19(1), 21-36.

Gerbic, P. (2006). Chinese learners and online discussions: New opportunities for multicultural classrooms. Research and Practice in Technology Enhanced Learning, 1(3), 221-237.

Gerbic, P. (2010). Getting the blend right in new learning environments: A complementary approach to online discussions. Education and Information Technologies, 15, 125-137.

Groves, M., \& O'Donoghue, J. (2009). Reflections of students in their use of asynchronous online seminars. Educational Technology and Society, 12(3), 143-149.

Hassam, A. (2007). Speaking for Australia: cross-cultural dialogue and international education. Australian Journal of Education, 51(1), 72-83.

Hew, K. F., Cheung, W. S., \& Ng, C. S. L. (2010). Student contribution in asynchronous online discussion: A review of the research and empirical exploration. Instructional Science, 38, 571-606.

Macdonald, J. (2008). Blended learning and online tutoring: Planning learner support and activity design. Aldershot, UK: Gower Publishing.

Ng, C. S. L., Cheung, W. S., \& Hew, K. F. (2009). Sustaining asynchronous online discussions: Contributing factors and peer facilitation techniques. Journal of Educational Computing Research, 41(4), 477511.

Vonderwell, S. (2003). An examination of asynchronous communication experiences and perspectives of students in an online course: A case study. Internet and Higher Education, 6, 77-90.

Vonderwell, S., Liang, X., \& Alderman, K. (2007). Asynchronous discussions and assessment in online learning. Journal of Research on Technology in Education, 39(3), 309-328.

Woodley, C., \& Pearce, A. (2007). A toolkit for internationalizing the curriculum at VU. Retrieved November 2010, from http://tls.vu.edu.au/vucollege/staff/internationalisation.html

Yin, R. K. (2009). Case study research: Design and methods. Thousand Oaks, California: Sage Publications.

Yin, R. K. (2010). Qualitative research from start to finish. New York: Guilford Publications.

Zhu, E. (2006). Interaction and cognitive engagement: An analysis of four asynchronous online discussions. Instructional Science, 34, 451-480. 


\section{Appendix \\ Online Discussion Assignment}

\section{Aim}

This assignment is aimed at familiarizing you with academic theory relating to implementation of human resource information systems. It is envisaged that you will use these references, together with additional references, in your research assignments.

\section{Learning outcomes}

On successful completion of the assessment you will be able to:

- demonstrate knowledge of the administrative and strategic value of an HRIS;

- demonstrate knowledge of the change management issues involved in the implementation of an HRIS;

- show evidence of enhanced personal knowledge of HRIS issues, based on academic articles.

\section{Readings:}

Dong, L. (2008). Exploring the impact of top management support of enterprise systems implementations outcomes. Business Process Management Journal, 14(2), 204-218.

Tansley, C., \& Newell, S. (2007). Project social capital, leadership and trust: A study of HRIS development. Journal of Managerial Psychology, 22( 4), 350-368.

Tansley, C., Newell, S. \& Williams, H. (2001). Effecting HRM-style practices through an integrated human resource information system: An e-greenfield site? Personnel Review, 30(3), 351370 .

Discussion questions will be posted in Blackboard on 13 August. The discussion will close on 17 August.

You will be randomly assigned to discussion groups of four/five and will need to discuss four/five questions: at least one on each of the above articles. Each member of the group should start one (and only one) discussion thread. Each member of the group must end the discussion they opened with a summary.

Your discussions will be individually assessed on:

- Effective participation including commencing early and participating in the discussions throughout the discussion period.

- Ability to discuss rather than simply post answers.

- Demonstration of conceptual understanding.

\section{Reflection and annotated bibliography}

- Reflect on the value of this on-line discussion as a learning experience (a personal reflection of no more than half a page). No references required.

- Write an annotated bibliography* of the three references

*Use the following website for guidelines on writing an annotated bibliography:

http://www.lc.unsw.edu.au/onlib/annotated bib.html 


\section{Marking criteria}

Reflection:

Annotated bibliography:

On-line discussion:

TOTAL MARKS

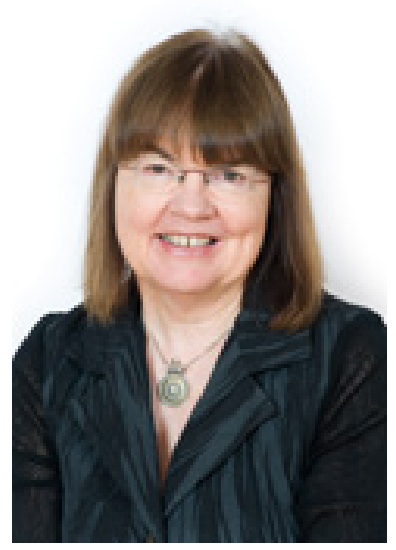

5 marks

15 marks

40 marks

$/ 60 \div 4=/ 15 \%$

\section{Biography}

Penny Bassett is a lecturer in Management and Information Systems at Victoria University in Melbourne, Australia. She has research interests in internationalization of the curriculum and e-learning, having participated in projects in both areas. Penny has been recognized for her contribution to teaching and learning in being awarded Victoria University's Vice-Chancellor's Award for Excellence in Teaching and Learning and an Australian Learning and Teaching Council (ALTC) Citation for Outstanding Contributions to Student Learning. 